\title{
BIM-BASED REVERBERATION TIME ANALYSIS
}

SUBMITTED: July 2020

REVISED: December 2020

PUBLISHED: February 2021

EDITOR: Žiga Turk

DOI: $10.36680 /$ j.itcon.2021.003

Mazdak Nik-Bakht, Assistant professor,

Department of Building, Civil and Environmental Engineering, Concordia University; mazdak.nikbakht@concordia.ca

Joonhee Lee, Assistant professor, Department of Building, Civil and Environmental Engineering, Concordia University; joonhee.lee@concordia.ca

Soheil Hadian Dehkordi, Graduate student, Department of Building, Civil and Environmental Engineering, Concordia University; soheil.hadiandehkordi@mail.concordia.ca

SUMMARY: Building Information Modeling (BIM) can store information of building elements and provide a computational platform for physical analyses for building systems. BIM can resolve several problems throughout various phases of design (as well as construction and operation). While use-cases such as daylight or energy analysis widely take advantage of this computational power, there is no integrated acoustical analysis tool or any external programs with acceptable interoperability within the BIM ecosystem. This study investigates the possibility of developing a BIM-based calculation method based on the most widely used design authoring tool in North America, i.e., Autodesk Revit, to estimate the acoustical properties of buildings with acceptable accuracy and details.

A novel algorithm is designed to calculate reverberation time (RT), one of the most critical acoustic indicators of building spaces. The algorithm extracts geometric information from the BIM (i.e., the model); matches it with the physical properties provided by an open-source library; performs the analysis; visualizes the results on the model. The tool is tested over several case studies, and the results have been verified and validated using other existing methods. In the paper, we have studied the acoustical properties of an educational building using the designed tool under various scenarios.

KEYWORDS: Building Information Modeling, Reverberation Time, acoustical analysis, OpenMAT, Sabine's formula, Dynamo.

REFERENCE: Mazdak Nik-Bakht, Joonhee Lee \& Soheil Hadian Dehkordi (2021). BIM-based reverberation time analysis. Journal of Information Technology in Construction (ITcon), Vol. 26, pg. 28-38, DOI: $10.36680 /$ j.itcon.2021.003

COPYRIGHT: () 2021 The author(s). This is an open access article distributed under the terms of the Creative Commons Attribution 4.0 International (https://creativecommons.org/licenses/by/4.0/), which permits unrestricted use, distribution, and reproduction in any medium, provided the original work is properly cited. 


\section{INTRODUCTION}

As a product and a process, BIM (Building Information Model) facilitates the integration of data analysis for architects, engineers, and construction (AEC) professionals by providing an information-centric platform. BIM is a platform for storing and exchanging data from the whole lifecycle of a building in a dynamic fashion that can be modified, updated, and queried. It can be defined as a visual database used by all project stakeholders for sharing their knowledge in one central model to enable comprehensive and cross-disciplinary solutions for various stages of the lifecycle. BIM provides the right tools for building performance analysis in the design phases to improve the building's design beyond aesthetic and engineering qualities and cover sustainability and post-occupancy attributes. Although various energy-related (typically energy consumption and daylighting) analysis methods have been integrated into the BIM platforms, there has been a lack of an inclusive tool to integrate the acoustical analysis in these platforms.

The acoustic conditions in a building significantly affect occupants' comfort (Lee et al., 2017) and in most cases, the consequences of an acoustically poorly designed space cannot be easily solved during the lifetime of the building. It is more efficient to perform the acoustical analysis at the early design phases. Acoustic specialists and experts have recently put an effort to adopt BIM compliant software tools into their projects. The resulted tools mostly retrieve data from a BIM model and use them in acoustical simulation software through manual modification of the model geometry (Kim et al., 2013). However, the programs designed for acoustical analysis are not acceptably interoperable with the BIM software tools, and the currently available add-ons are not comprehensive enough.

The interoperability issues between the BIM-based software and acoustical analysis software limit the applications in practice and create obstacles for taking advantage of full BIM potentials (i.e., design automation and integration). One possible solution to this problem can be performing acoustical simulations locally in the design authoring software. The integration can increase productivity by facilitating feedback loops between the architect and the acoustic engineer. More importantly, the coordination among the architectural and acoustic models will keep both models up-to-dated with impacts from the other discipline's changes at various levels of development (LODs) of the model. The current practice of transferring geometric and non-geometric data from BIM and plugging them into acoustic simulation software (and vice-versa) is time-consuming and error-prone. Moreover, the accuracy of acoustic analysis results will depend on the user's expertise (Kim et al., 2013). The process is also unidirectional from BIM to the acoustic software. The simulation outputs cannot be easily retrieved back to the BIM, and changes in the architectural model can not be automatically coordinated in the acoustic model (Wu \& Clayton, 2013). Thus, the present paper aims to support acoustic simulation as a native BIM-use to improve the accuracy and decrease the time/efforts required for acoustical analysis and create bi-directional feedback loops between architectural and acoustical models of a building.

We have four primary objectives: (1) extracting geometry data required for acoustical analysis from the BIM; (2) enriching BIM with acoustic-related data via an external open format database; (3) calculating reverberation time by taking the effect of architectural and non-architectural elements into consideration; and (4) visualizing the simulation results in the BIM. The method needs to be dynamic and automatically updated to let the users investigate the results of using various design alternatives into the building's acoustical performance. The results will provide an accurate estimation of the reverberation time, considering different finishes for architectural elements, doors, windows, curtain walls, and the furniture. After a critical review of the similar works reported in the literature, we will explain our proposed algorithm and the implementation method in the rest of the paper. Then we will apply the method to a case study project and report/discuss the results. The paper will conclude with the elaboration of the main findings and contributions as well as limitations of the work and recommendations for future research.

\section{PREVIOUS WORKS}

Wong and Fan (2013) evaluated the use of BIM for sustainable designs. They studied the functions, benefits, and achievements of BIM inherency and BIM-based analysis tools. They concluded that the lack of interoperability among BIM and software tools that support various analyses limits BIM application in the AEC industry. Over the last decade, there have been several attempts to integrate acoustic analysis into BIM-related software during the conceptual design phase. A previous study on code compliance in France effectively used BIM with the European Enriched Virtual Environments project (EVE). EVE is a developed program, which supports the 
different aspects of a building's performance, including environmental noise and indoor noise compliance against the French Building Code for the Buildings and Construction. The simulation module of EVE includes acoustic simulation codes, originated from a software called ACOUBAT-Son (Maïssa et al., 2002). Juneja (2015) aimed to link standards for classroom acoustics and real-time practice of acoustical design of classrooms using BIM, acoustic simulation, and multi-criteria decision modeling. The author calculated acoustic parameters of early decay time, reverberation time $\left(\mathrm{RT}_{60}\right)$, and sound pressure levels for classrooms by importing data from an Industry Foundation Classes (IFC) model.

BIM-based software products with acoustic simulation capabilities have been mostly used to evaluate noise generated by mechanical, electrical, and piping (MEP) systems. EASE is one of the acoustic simulation software tools which can extract various kinds of data, including geometry, acoustic information, and finishes, from CAD files. Kim et al. (2013) used this tool in conjunction with Autodesk Ecotect and Autodesk Revit to analyze noise levels, $\mathrm{RT}_{60}$, and binaural impulse response of an auditorium. Despite the successful application, this solution still performs the analysis outside the Revit environment and is unable to coordinate back with the BIM. Also, acoustic simulation specialized software, including EASE, has the disadvantage of a time-consuming procedure and a complicated process to rebuild the 3D model. Kirkegaard and Kamari (2017) proposed extracting geometrical data from the model and adding physical information such as absorption coefficients to Revit's material library to bridge the gap of lack of integration of acoustic analysis with Revit. The study utilized this method to estimate acoustical properties such as $\mathrm{RT}_{60}$. Although the idea of populating the model with physical properties would be helpful for customized solutions, using a generic external database with all needed properties would be more intuitive in the early design phases.

Several efforts are reported in the literature to integrate the acoustic analysis process in design authoring tools such as Revit. Wu and Clayton (2013) developed a BIM-based acoustic simulation framework using the Revit API (Application Programming Interface) to analyze a single room's acoustical performance. The computational load required for this proposed solution is high if the framework is applied to a full-scale building. Tan et al. (2017) also used Revit API to extract geometric data for a concert hall, assign absorption coefficients to indoor materials and transfer it to the commercial finite element solver COMSOL through the IFC standard. The authors calculated $\mathrm{RT}_{60}$ for the concert hall with different layout alternatives and various source types. However, neither method could return the calculated acoustic properties and simulation results back to the BIM (model).

Other researchers have tried to use Dynamo to create tools for performing acoustic calculations over the Revit models. One of those tools is Acustamo (Andrea, 2015), a Revit add-on utilizing a ray-tracing simulation technique. The inputs include room surfaces, sound sources, and maximum reflection orders. The output will be poly-curves indicating reflection paths useful for acoustical analysis. Implementing this tool in practice can be tricky since room surfaces need to be manually added via the Dynamo interface.

To sum up, while there are software tools for acoustical analysis of indoor spaces, and although some of those tools could be linked with design authoring tools (such as Autodesk Revit), the linkages are mostly one-directional, and the transition needs experts' manual intervention. Thus, in practice, the status quo is to remodel the design in alternative acoustical analysis platforms rather than including such analyses as one of the links in the BIM process chain. On the other hand, the available tools (CATT-Acoustic, 1998; EASE, 2011; ODEON, 1991) are either too complex to be applied at large-scale (or high LOD) models; or are not essentially designed to capture the effect of non-architectural elements such as suspended ceilings, columns, furniture, doors and windows which can have a considerable effect. Besides the acoustic surfaces, non-architectural elements play a significant role in reducing $\mathrm{RT}_{60}$ and ignoring them in the calculations, make the results less accurate.

\section{METHODOLOGY}

In response to the gaps identified in the literature, the present study aims to develop a fully BIM-based process to improve the evaluation of buildings' indoor acoustic performance by calculating the $\mathrm{RT}_{60}$ of different rooms. We selected Autodesk Revit (as the most common BIM modeling software in the literature and the North American AEC industry (McCabe et al., 2019; NBS, 2020) and aim to return calculated $\mathrm{RT}_{60}$ values and store it back in the model, as new attributes for rooms. The algorithm shown in Figure 1 is an overview of the significant steps and checkpoints in the developed method. The current paper is based on the authors' previous study, which developed a preliminary Dynamo algorithm to calculate the $\mathrm{RT}_{60}$ of rooms in a model using Sabine's formula (Erfani et al., 2019). The previous algorithm had limitations, including the assumption of the same material for horizontal 
surfaces (i.e., floors and ceilings) and ignorance of the furniture elements. The algorithm used in this study utilizes various points of geometry analysis to address the intersecting surfaces of furniture and architectural elements to improve the accuracy of $\mathrm{RT}_{60}$ estimation. We have used Dynamo to implement the solution in Revit; however, the method is general and can be implemented in other design authoring platforms.

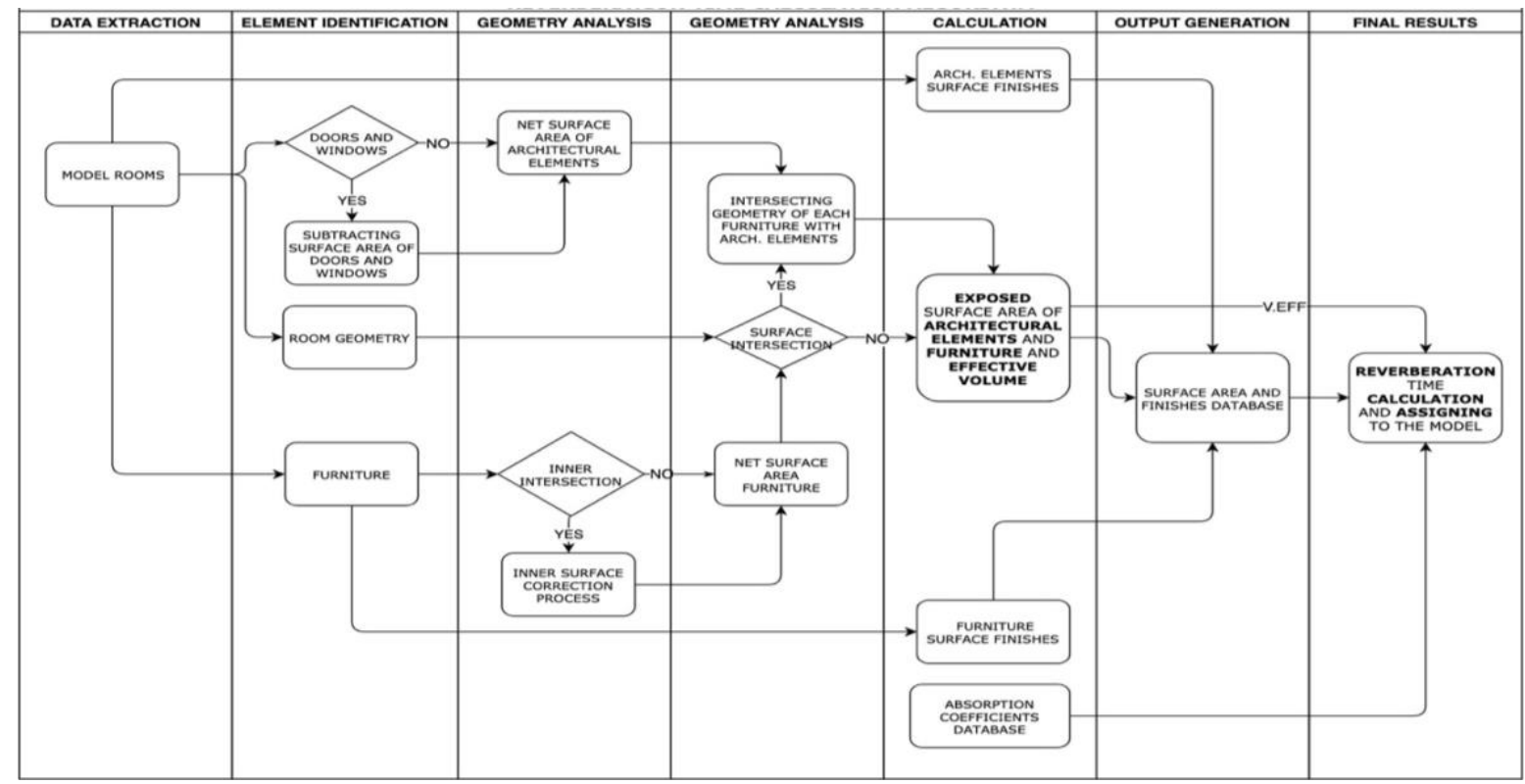

FIG. 1: High-level architecture of the proposed solution to implement $R T_{60}$ calculation in BIM.

The model requires a precise definition of objects involved in the calculation of $\mathrm{RT}_{60}$, i.e., vertical and horizontal surfaces in rooms. This ideally abides by the representation of wall, floor, roof, and furniture systems as well as their assemblies, as meeting the expectations of LOD300 and above. Nevertheless, the algorithm can successfully work with elements of lower LOD (i.e., LOD200) as long as the geometry, shape, and orientation of bounding surfaces are in place; finish materials are assigned to the surfaces; rooms are defined; and, optionally, the geometry and finish material of the furniture are present in the model. The elements of each room, including architectural and non-architectural, are extracted and categorized in dictionary data structures to take advantage of nonnumerical indexes. The developed code processes the raw information (i.e., gross areas of walls, ceilings, floors, windows, doors, curtain walls, and furniture) and geometries (single geometries and intersections of geometries) extracted from the model into values such as "Exposed Areas" and "Net Areas". These new values are then used for the calculation of the total absorption area in each room. Figure 2 illustrates an overview of the code flowchart to implement the algorithm. Major components of the code are further explained below in detail. Several custom extensions, including Archilab, Bakery, ClockWork, Python, Rhythm, and Springs, were used to implement the code in Dynamo.

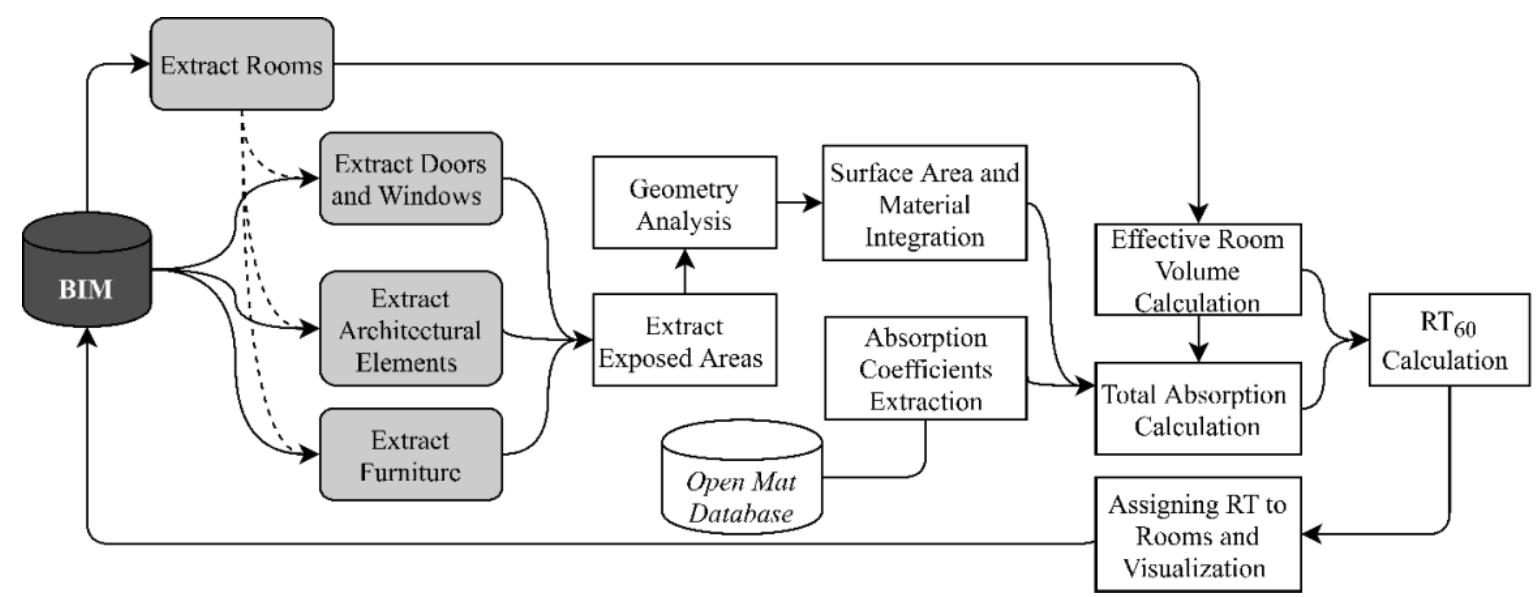

FIG. 1: Final Dynamo code overview, different sections, and their function 


\subsection{Data extraction}

One challenge in working with elements' properties in a Revit model is to maintain the data structures and links between them in a fashion that can be referenced without error. Automatic linkage between each surface and acoustic absorption coefficients can be cumbersome and delicate. Such a structure should not be prone to error when data/elements sorting changes. Required data in the calculation of $\mathrm{RT}_{60}$ can be categorized into architectural elements' properties (including area, finishes, and geometry of rooms) and non-architectural elements (i.e., the furniture). We initially tested the algorithm on a variety of simplified models including one and two room(s), with and without furniture, doors, and windows, as well as non-rectangular rooms (and combinations of these cases). In each case, we resolved the errors raised in data extraction. One main contribution of our algorithm and the code is considering the effect of openings, furniture, and non-architectural components in the absorption and $\mathrm{RT}_{60}$ calculations. Those components can significantly improve the calculation accuracy compared to the actual measured RT60 by utilizing more accurate sound absorption areas.

All architectural elements and their corresponding surface area and finish material are extracted by identifying rooms in the Revit model. This enables the code to consider different materials for walls, ceiling, and floor for each room separately and store them in a properly structured dictionary by room and surface types for future steps of the analysis. The code also can identify curtain walls separately from simple walls and windows. Gross areas and finishes for ceilings, floors, and curtain walls in each room are stored separately. For non-architectural elements, by identifying all the existing furniture in the model and their location, the needed information, including surface areas and related materials, are extracted for each element. The main technical challenge was that some Revit furniture families are built with geometries that have internal surfaces. These internal surfaces can be mistakenly included in the overall surface area of the furniture in $\mathrm{RT}_{60}$ calculations. On the other hand, these separate geometries of a single model might have different materials with different absorption coefficients.

In the next step, each element was translated into Dynamo geometries. Some furniture families are built of multiple surfaces with various finish material (e.g. a metal desk with a wood desktop). Unionizing these geometries gives the proper total surface areas, but not the portion of the areas that correspond to each finish. To solve this, the comparison between a unified geometry surface area to the summation of individual geometry surface areas provides a specific coefficient for each object finish that can be later multiplied by the surface area of each material. For example, if the surface area of the wooden desktop is $\mathrm{A}_{\mathrm{T}}$ and the total surface area of the metal desk base is $\mathrm{A}_{\mathrm{B}}$, then the parameter alpha for the wooden surface is evaluated as $\alpha_{T}=A_{T} /\left(A_{B}+A_{T}\right)$. Multiplying the unified geometry surface area by $\alpha_{T}$ provides the net surface area with wood as the finish material. The results are specific net surface areas for each material used in the element. This step provides furniture geometries (exploded and unified), furniture net areas, and finishes in each room. For doors and windows, the total area of those elements located in each room is extracted firstly. These elements are stored separately and are indexed as "Doors" and "Windows" (rather than by their materials). This method is selected because the absorption coefficients for these components are provided by the type instead of by the finish material typically. This module of the code provides three outputs: doors area and finishes in each room; windows area and finishes in each room; and total fenestration area.

\subsection{Geometry Analysis}

The main target of the geometry analysis component of the code was to calculate net and exposed areas for architectural and non-architectural surfaces. Firstly, the net area of the walls was calculated by subtracting doors and windows surface areas in each room from the walls (curtain walls are separated in these calculations). Secondly, a major step is to identify the "exposed" surface areas of architectural and non-architectural elements (i.e., those surfaces inside a room, which are exposed to the sound field). While for each category of architectural elements, the total exposed area can be calculated as the summation of areas for all similar elements (i.e., walls) in that room; for the furniture, exposed surface areas are unique for each furniture instance and has to be calculated independently.

To evaluate the exposed areas for the furniture, the rooms and furniture are converted into Dynamo geometries (solids), and the required areas are extracted from intersections of these solids. To better explain the procedure, Figure 3 provides a schematic view of furniture in a room and showcases the areas which need to be extracted. In this figure, $S_{1}$ and $S_{2}$ are first directly extracted from the model, and then $S_{3}$ is calculated by subtracting the solid geometry of all furniture elements inside the room $\left(S_{2}\right)$ from the room solid geometry $\left(S_{1}\right)$ and calculating the 
surface area of the resulting solid. The exposed surface area of furniture $\left(\mathrm{S}_{4}\right)$ and intersection area of furniture and the room $\left(\mathrm{S}_{5}\right)$ through the following equations.

$$
S_{4}=\left(S_{1}+S_{2}-S_{3}\right) / 2 \quad \text { and } \quad S_{5}=S_{2}-S_{4}
$$

In which: $\mathrm{S}_{1}$ : Total room boundary areas; $\mathrm{S}_{2}$ : Total furniture surface areas; $\mathrm{S}_{3}$ : Total surface area of the solid resulted by subtracting furniture geometry from room geometry; $\mathrm{S}_{4}$ : Exposed surface area of each furniture; and $\mathrm{S}_{5}$ : Intersection surface area of the furniture and the room. Having the values of $\mathrm{S}_{1}$ through $\mathrm{S}_{5}$, we can then calculate the exposed area of architectural elements. The geometry subtraction of furniture from the room $\left(\mathrm{S}_{3}\right)$ is firstly intersected with two planes (at the floor and ceiling height) to find $S_{7}$ and $S_{9}$. Then, by taking away $S_{5}, S_{7}$, and $S_{9}$ from $S_{3}$, the net exposed surface area of walls $\left(S_{8}\right)$ will also be identified. This completes the calculation of exposed areas for all architectural (i.e., $\mathrm{S}_{7}, \mathrm{~S}_{8}$, and $\mathrm{S}_{9}$ ) and non-architectural (i.e., $\mathrm{S}_{4}$ ) elements. It must be mentioned that this procedure, particularly for multiple/complex furniture items, is time-consuming.

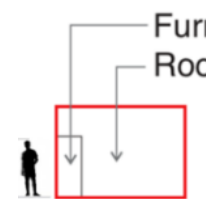

$\mathrm{S}_{1}$

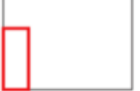

$\mathrm{S} 2$

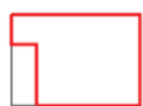

$\mathrm{S}_{3}$

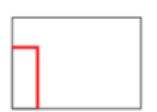

$\mathrm{S}_{4}$

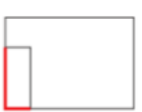

$\mathrm{S}_{5}$

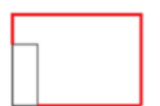

S6

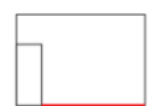

$\mathrm{S}_{7}$

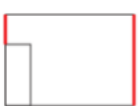

S8

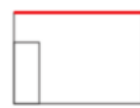

$\mathrm{S}_{9}$

FIG 3: Extracting exposed areas for the furniture ( $S_{1}$ and $S_{2}$ are retrieved from the model. $S_{3}, S_{7}, S_{9}$ are calculated from geometry intersections. $S_{4}$ to $S_{6}$ as well as $S_{8}$ are calculated mathematically.)

\subsection{Acoustic material open database}

An acoustic material database is necessary to provide absorption coefficients of the finish material for all surfaces inside rooms. Today, researchers and acoustic consultants have access to many acoustic simulation programs. These applications can be commercial or open-source. The interoperability between different programs is, in many cases, problematic since they rely on internally developed database formats. Therefore, OpenMAT database project was initiated to support a detailed description of materials and provide acoustic professionals with an exchangeable database usable in acoustical simulation software (Schröder et al., 2013). The OpenMAT can store numerical data and meta-information of the material in an open Extensible Markup Language (XML) format. The available data are absorption coefficients, scattering coefficients, material price, and a photo of materials texture. Moreover, OpenMAT has both $\mathrm{C}++$ and Python library for external coding. We used a material database in OpenMAT format to provide absorption coefficient data for the common materials.

\subsection{RT60 calculation}

In this study, the calculations are based on Sabine's formula of reverberation time (Kinsler et al., 1999). The equation is:

$$
R T_{60}=\frac{0.161 * \mathrm{~V}}{\sum S \propto},
$$

where: $\mathrm{RT}_{60}$ : Reverberation Time (sec); V: volume of a room $\left(\mathrm{m}^{3}\right) ; \mathrm{S}$ : surface area of material $\left(\mathrm{m}^{2}\right) ; \alpha$ : absorption coefficient.

The absorption coefficients range from 0 (when no sound is absorbed) to 1 (when the entire sound is absorbed). Sabine's equation used in this study assumes a diffuse sound field for calculating the reverberation time. There are other equations for non-uniform absorption distribution in a room, but Sabine's equation is the most popular and suitable for predicting reverberation time for general purposes.

At this step, all the needed information is extracted, indexed, and categorized in structured data formats (Dynamo dictionaries) to be used for acoustical analysis. Compiling all the data, the corresponding material areas and their absorption coefficients in each room replace the element types (e.g., walls or furniture) in the dictionaries. Finally, the coefficients are linked to the surfaces, and the total absorption area for each room is calculated. The last geometric attribute to be calculated is "Effective Room Volume" ( $\left.\mathrm{V}_{\mathrm{EFF}}\right)$ that is found by subtracting furniture geometry volume from the room volume. 
The final step is to calculate $\mathrm{RT}_{60}$ in 6 main frequencies and assigning the calculated values to the room elements in the Revit model. The results are assigned to the project parameters that are defined in the Revit model at the final step. In order to visualize the results, we first color-code the $\mathrm{RT}_{60}$ values ('color weights' within the range of minimum and maximum $\mathrm{RT}_{60}$ ). Then the code creates extruded solids from room geometries and finally assigns the proper color weight to the solid representing each room.

\section{CASE STUDY}

In order to validate the developed system and examine the practicality and efficiency of this process in action, an educational facility at Concordia University in Montréal was studied. Autodesk Revit 2019 was selected as the BIM design authoring software, and the developed code in Dynamo was used to analyze the model of John Molson School of Business at Concordia. This building has 17 floors and 37,000 gross square meters of area. The building was opened in 2009 and is LEED Silver certified. The developed model is at LOD200, with some elements including architectural elements finishes at LOD300. Apart from the size, shape, and location, the algorithm requires the finish material of the walls, floors, and ceilings. Hence, in the wall composition of both exterior and interior walls, as well as floor and ceiling assemblies, we introduced the right material type and properties for the finish layer of the families. F shows the floor plan of level 6 in the model (as a sample) with the furniture.
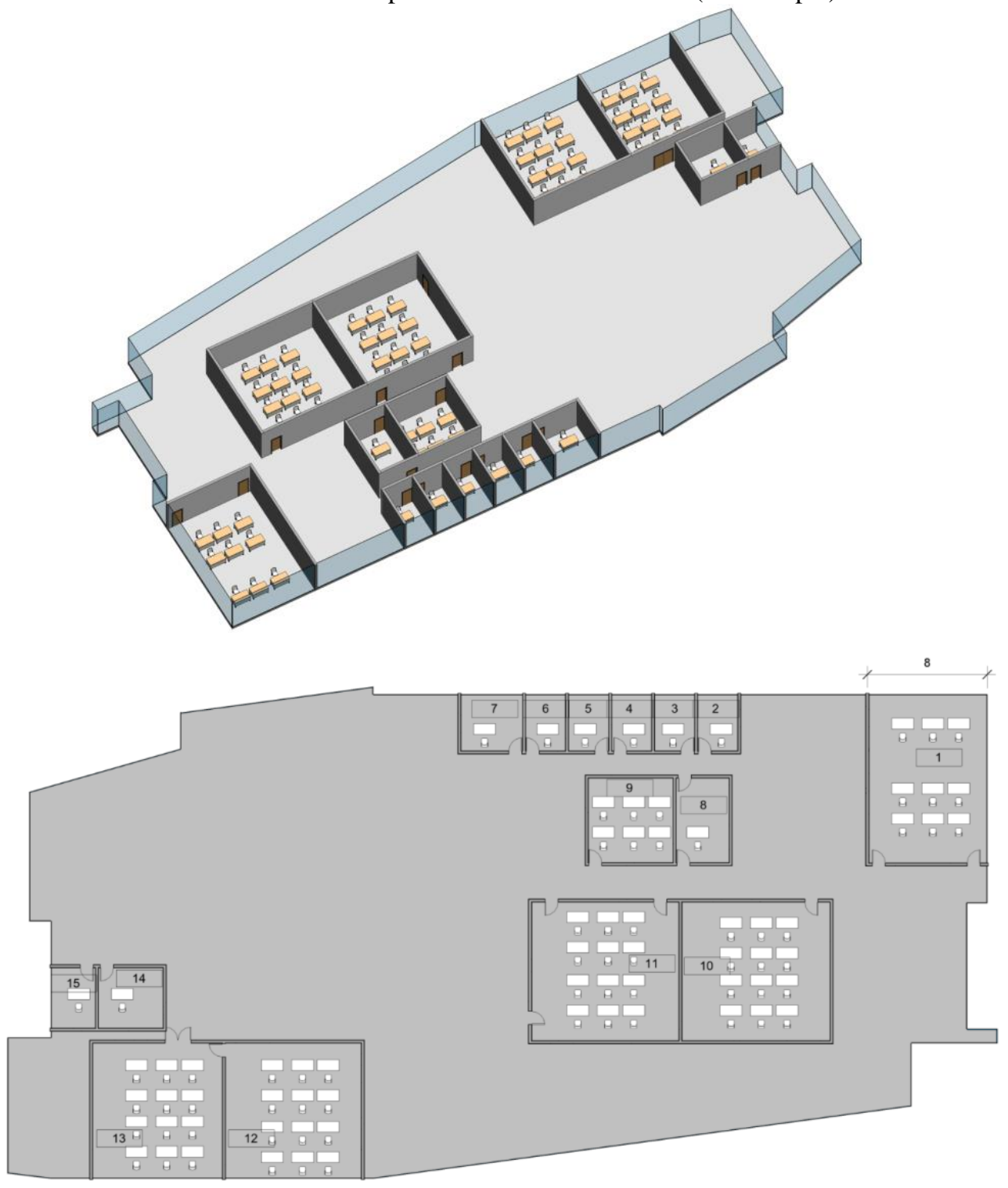

FIG. 4: Floor plan, Level 6 of the case study - Concordia University, John Molson Building 
Two scenarios are considered to investigate the effect of furniture on the Reverberation Time, with and without furniture. The surface finishes are plaster or gypsum wallboard, tiles on concrete, plaster or 600x600 ceiling tiles, metal, textile, and MDF. The corresponding absorption coefficients used for calculations are presented in Table 1.

Table 1: Absorption coefficients used in the project extracted from previous projects (Vorländer, 2007; Wojnowska \& Smardzewski, 2016)

\begin{tabular}{llllll}
\hline Finish & $\mathbf{1 2 5} \mathbf{H z}$ & $\mathbf{2 5 0 ~ H z}$ & $\mathbf{5 0 0 ~} \mathbf{H z}$ & $\mathbf{1 0 0 0 ~} \mathbf{H z}$ & $\mathbf{2 0 0 0} \mathbf{H z}$ \\
\hline Plastic (MDF) & 0.08 & 0.11 & 0.11 & 0.194 & 0.24 \\
Gypsum Wall Board & 0.15 & 0.1 & 0.06 & 0.04 & 0.04 \\
Ceiling Tile 600 $\boldsymbol{x} \mathbf{6 0 0}$ & 0.45 & 0.8 & 0.85 & 0.85 & 0.95 \\
Metal & 0.02 & 0.02 & 0.03 & 0.05 & 0.05 \\
Doors & 0.25 & 0.2 & 0.15 & 0.1 & 0.04 \\
Windows & 0.35 & 0.25 & 0.18 & 0.12 & 0.07 \\
Ceramic Tile & 0.01 & 0.01 & 0.02 & 0.02 & 0.02 \\
Wood (HPL) & 0.04 & 0.22 & 0.42 & 0.58 & 0.07 \\
Concrete & 0.02 & 0.02 & 0.03 & 0.03 & 0.03 \\
Glass & 0.1 & 0.05 & 0.04 & 0.03 & 0.04 \\
Plaster & 0.01 & 0.01 & 0.02 & 0.02 & 0.03 \\
\hline
\end{tabular}

\section{RESULTS AND DISCUSSION}

$\mathrm{RT}_{60}$ estimation results for Scenario 1 (without furniture) and 2 (with furniture) are presented in Table for rooms on the $6^{\text {th }}$ floor of the case study. Results with the non-furnished scenario show very high $\mathrm{RT}_{60}$ values in some cases. The maximum is $16.79 \mathrm{~s}$ for room number 10 at $250 \mathrm{~Hz}$ frequency. This is because the room is very reverberant without any absorbing surfaces in it. The $\mathrm{RT}_{60}$ values decrease when the furniture is added (scenario 2), with the maximum RT of $11.85 \mathrm{~s}$ for the same room, but at $125 \mathrm{~Hz}$ octave band frequency. It confirms that the effect of furniture is significant on the reverberation time and should not be excluded for the estimation, even in the early design phase. F shows how the reverberation time is affected by adding furniture to the rooms. The effect of adding furniture is more significant for larger rooms by up to $7.87 \mathrm{~s}$ decrease of the reverberation time, especially in higher frequencies.

Table 2: Reverberation Time estimation results for the rooms on the $6^{\text {th }}$ floor of the case study with and without furniture

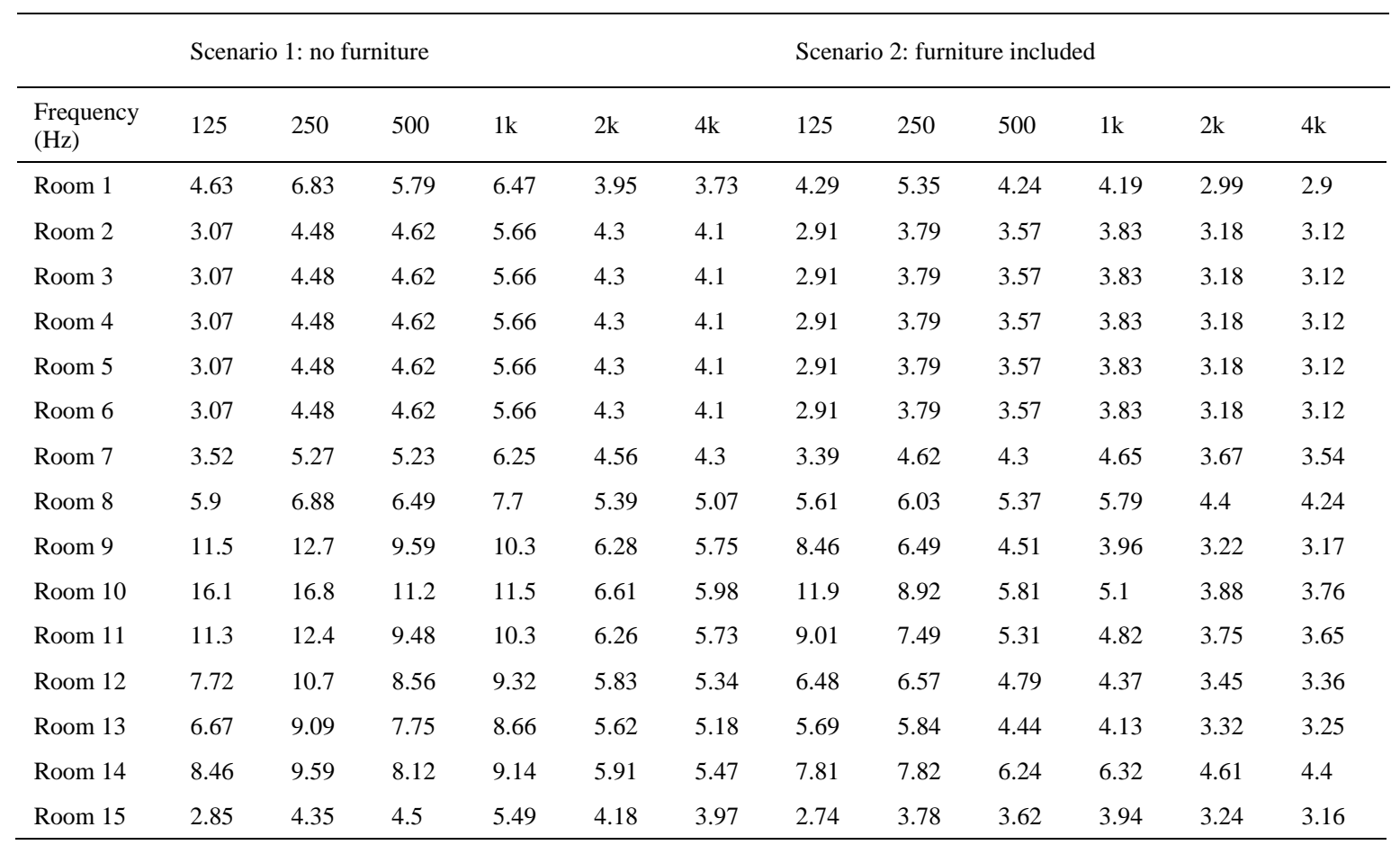




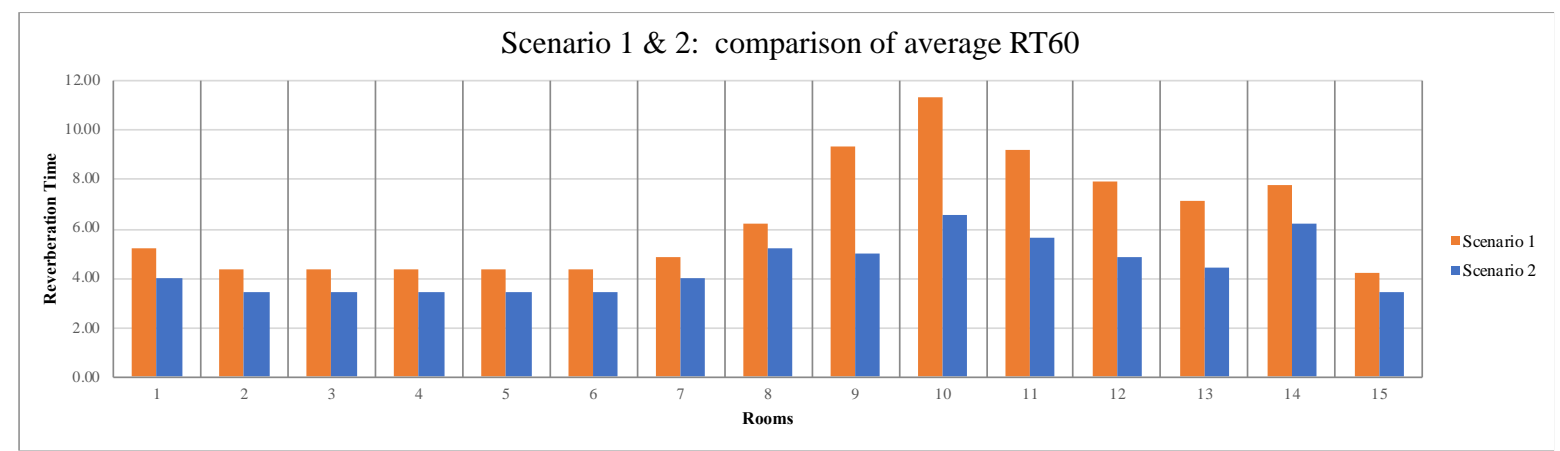

FIG 5: Comparison of the average RT (from $125 \mathrm{~Hz}$ to $4 \mathrm{kHz}$ octave band) for Scenario 1 (without furniture) and Scenario 2 (with furniture)

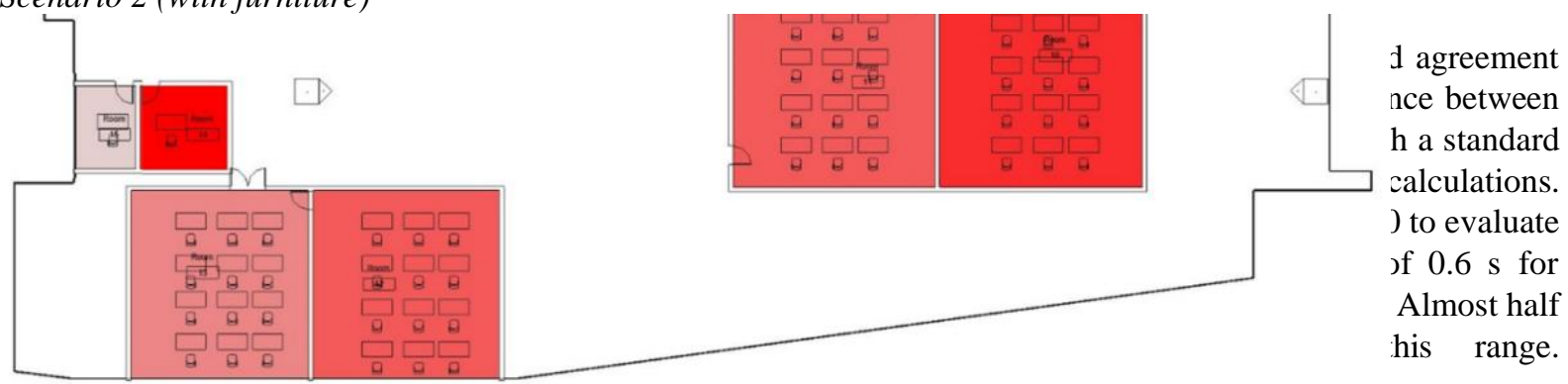

FIG 2 presents an example of visualization for the simulation results in Revit software. We selected a color code covering shades of red to indicate which rooms are above the recommended range. The darker red denotes higher reverberation time.

Table 2: Results comparison for Reverberation Times for sample room including furniture

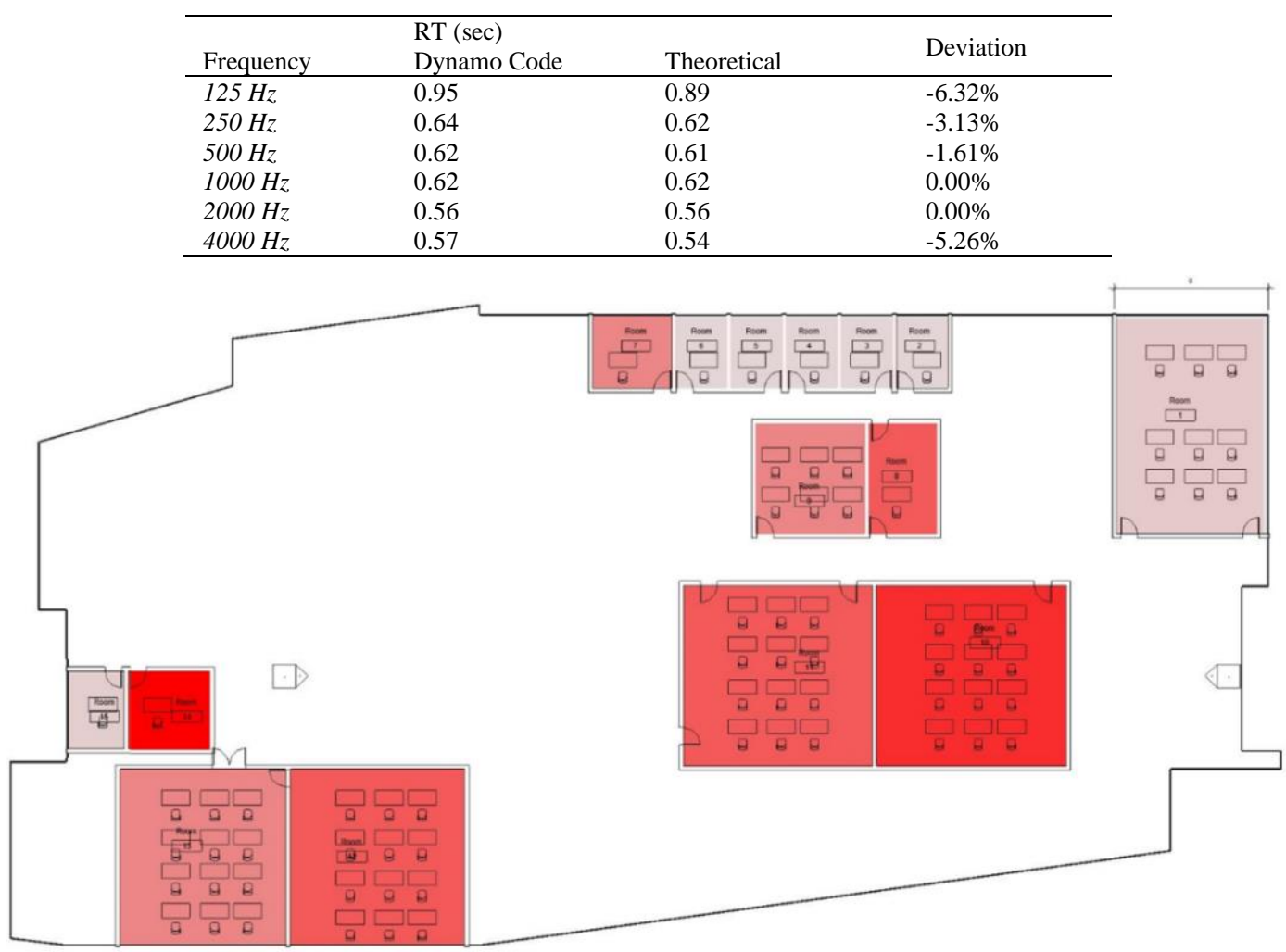

FIG 2: Color-coded RT at $500 \mathrm{~Hz}$ frequency for floor plan level 6, furnished 
Finally, it is worthwhile to mention that since the proposed method is based on the application of Sabine's formula, the information acquired from BIM is limited to the geometry and surface finishes. Therefore, the calculated $\mathrm{RT}_{60}$ are not expected to change as the LOD of the model increases (unless there would be changes in the spaces, location, size, shape, finish material, or orientation of the vertical and/or horizontal surfaces, or the furniture system). However, if more advanced RT calculation techniques are to be implemented, then detailing, fabrication assembly information, or even introducing the interfaces among elements may affect the results. The sensitivity of RT calculation under such methods to the LOD of the model remains an interesting topic for future investigations.

\section{CONCLUSIONS}

This study proposed an improved BIM-integrated method to evaluate the reverberation time of spaces and store/visualize them within the model, and implemented it within the environment of Autodesk Revit. The data extracted from BIM include architectural and non-architectural elements, their type, location, properties such as surface area and material, and the possible intersections with other elements. Data from BIM was enriched by the acoustical information extracted from an external open-access and open-source standard database. The possibility of automated coordination between design and acoustical analysis (i.e., updating the model and re-analyzing it with new properties introduced in the model) makes our proposed solution more useful compared to other existing acoustic analysis software tools (outside the design authoring environment). This feature provides the user with the ability to test different design/retrofit scenarios. It can also become handy for educational purposes for understanding the acoustical properties and effects of different surfaces.

The results confirmed that a model-based acoustical analysis of interior spaces can be successfully done within the Revit environment using the algorithm developed in Dynamo. The model can be a simple empty room or a room with non-architectural and non-laminar surfaces such as the furniture. The proposed method for including the effect of furniture, which is based on detailed exposed surface areas of each component in the room and their corresponding finish materials, is proven to be working correctly. The method considers exposed areas and excludes hidden areas not applicable to the calculation of reverberation time.

While we developed our method on the foundation of previous studies and the approach used in this paper is similar to some previous works (e.g., using Revit being used as the BIM authoring software and $\mathrm{RT}_{60}$ being selected as the building acoustic performance factor), the present study contributes to this field by (i) calculating $\mathrm{RT}_{60}$ within the Revit environment and avoiding the use of IFC exports (and subsequent interruptions/data loss associated with it); (ii) providing access for the acoustic analysis to both geometric and non-geometric parameters, without the need to regenerate the 3D model; (iii) modeling the effect of furniture successfully and realistically; (iv) using an open acoustic material database which can be completed and shared with others on the fly; and (v) creating a bidirectional path and a closed feedback loop between architectural and acoustical models.

The limitations of this study range from the scope (being limited to the calculation of reverberation time) to the assumptions applied and the algorithmic limitations. The future versions of the system can be extended to simulation and calculation of factors such as sound level and structure-borne noise. Additionally, the system must be tested by models with a higher level of detail. Future works can study other forms of construction and building types. Integrating OpenMat databases in BIM-based simulations requires better semantic integration. For example, this can include developing and using the "Material Universal ID" system, rather than searching material by their names (as being done in our current software). An alternative solution can be to enrich the material database of Revit with more detailed material properties regarding acoustical behavior. The latter, however, will need the software vendor's initiatives and will remain a software-proprietary solution. 


\section{REFERENCES}

Acoustical Society of America. (2010). ANSI/ASA S12.60 PART 1: American National Standard Acoustical Performance Criteria, Design Requirements, and Guidelines for Schools, Part 1: Permanent Schools.

CATT-Acoustic. (1998). Retrieved December 21, 2020, from https://www.catt.se/

EASE. (2011). Retrieved December 21, 2020, from https://ease.afmg.eu/

Erfani, K., Mahabadipour, S., Nik-Bakht, M. and Lee, J. (2019). BIM-based Simulation for Analysis of Reverberation Time, In IBPSA Building Simulation 2019, Rome, Italy.

Juneja, P. (2015). Life Cycle Value Tradeoff of Noise Mitigating Measures using BIM-Simulation and Multi Criteria Decision Modeling: Revisit to Healthy School Environments, International Journal of Facility Management 6(1): 15.

Kim, S., Coffeen, R. C. and Sanguinetti, P. (2013). Interoperability Building Information Modeling and acoustical analysis software - A demonstration of a performing arts hall design process, In Meetings on Acoustics, Vol. 19, Presented at the ICA 2013, Montreal, Canada: Acoustical Society of America.

Kinsler, L. E., Frey, A. R., Coppens, A. B. and Sanders, J. V. (1999). Fundamentals of Acoustics, 4th ed., Wiley.

Kirkegaard, P. H. and Kamari, A. (2017). Building Information Modeling (BIM) for Indoor Environmental Performance Analysis (Technical report No. CAE-TR-3), Denmark: Department of Engineering, Aarhus University.

Lee, J., Francis, J. M. and Wang, L. M. (2017). How tonality and loudness of noise relate to annoyance and task performance, Noise Control Engineering Journal 65(2): 71-82.

Maïssa, S., Frachet, J., Lombardo, J., Bourdeau, M. and Soubra, S. (2002). Regulation checking in a Virtual Building, In CIB W78 Conference, Århus, Denmark.

McCabe, B., Shahi, A., Zhang, L. H., Whitell, M., \& Cao, Y. (2019). 2nd Annual BIM Report-Canada wide survey. University of Toronto.

NBS. (2020). 10th National BIM Report. National Building Specification.

ODEON. (1991). Retrieved December 21, 2020, from https://odeon.dk/

Schröder, D., Pohl, A., Drechsler, S., Svensson, P., Vorländer, M. and Stephenson, U. M. (2013). openMat Management of Acoustic Material (Meta-)Properties Using an Open Source Database Format, In AIADAGA 2013, Presented at the AIA-DAGA 2013 International Conference on Acoustics, Merano, Italy.

Tan, Y., Fang, Y., Zhou, T., Wang, Q. and Cheng, J. C. P. (2017). Improve Indoor Acoustics Performance by Using Building Information Modeling, In 34th International Symposium on Automation and Robotics in Construction, Taipei, Taiwan.

Vannini Andrea. (2015, February 15). Acustamo released!, Dynamo. Retrieved July 21, 2020, from https://forum.dynamobim.com/t/acustamo-released/1091

Vorländer, M. (2007). Auralization: fundamentals of acoustics, modelling, simulation, algorithms and acoustic virtual reality, 1st ed., Springer Science \& Business Media.

Wojnowska, M. and Smardzewski, J. (2016). The impact of construction and forms of furniture on the acoustic properties of offices, In IFC 2016 International Furniture Congress, Mugla, Turkey, pp. 204-207.

Wong, K. and Fan, Q. (2013). Building information modelling (BIM) for sustainable building design, Facilities 31(3/4): 138-157.

Wu, C. and Clayton, M. J. (2013). BIM-based acoustic simulation framework, In 30th CIB W78 International Conference, Beijing, China, pp. 99-108. 